\title{
Influences of Cooling Rate After Solution Treatment on Microstructural Evolution and Mechanical Properties of Superalloy Rene 80
}

\author{
Shuang Gao ${ }^{1} \cdot$ Jie-Shan Hou $^{1} \cdot$ Kai-Xin Dong ${ }^{1} \cdot$ Lan-Zhang Zhou ${ }^{1}$
}

Received: 10 July 2016/Revised: 8 September 2016/Published online: 18 October 2016

(C) The Chinese Society for Metals and Springer-Verlag Berlin Heidelberg 2016

\begin{abstract}
Influences of the cooling rate after solution treatment on microstructural evolution and mechanical properties of Rene 80 nickel-based superalloy were investigated by optical microscopy, scanning electron microscopy, transmission electron microscopy and mechanical test. Results showed that the high cooling rate decreased the size of secondary $\gamma^{\prime}$ particles in the supersaturated matrix, but led to a high coarsening rate of $\gamma^{\prime}$ particles during subsequent aging treatment. Despite various coarsening rates, the size and morphology of $\gamma^{\prime}$ particles in the final microstructures of all samples were close due to the long enough holding time to an equilibrium state. During the aging of $870{ }^{\circ} \mathrm{C} / 2 \mathrm{~h}$, primary $M \mathrm{C}$ started to decompose with the carbide reaction: $M \mathrm{C}+\gamma \rightarrow M_{6} \mathrm{C}$ or $M_{23} \mathrm{C}_{6}+\gamma^{\prime}$. And a number of observations showed that the coarsening of $\gamma^{\prime}$ particles on grain boundaries resulted in the depletion of $\gamma^{\prime}$ during aging treatment. The test results indicated that high cooling rate resulted in the presence of quench crack, and the air cooling method following solution treatment was an optimum heat treatment method for Rene 80.
\end{abstract}

KEY WORDS: Ni-based superalloy; Cooling rate; $\gamma^{\prime}$ Precipitates; Ripening theory; Heat treatment; Microstructural evolution

\section{Introduction}

Nickel-based superalloys have been widely applied to the aerospace field and gas power generation industries due to their excellent high-temperature creep resistance, superior high-temperature corrosion resistance and high-temperature phase stability [1-3]. As service requirements are continuously increasing, the alloying degree of nickel-based superalloys improves gradually $[4,5]$. In general, it achieves

Available online at http://link.springer.com/journal/40195

Lan-Zhang Zhou

1zz@imr.ac.cn

1 Institute of Metal Research, Chinese Academy of Sciences, Shenyang 110016, China the goal of solid solution strengthening by the addition of alloying elements such as Co, Mo and W [6, 7]. The precipitation strengthening of the alloy can be enhanced by adding the formation elements of strengthening phase $\gamma^{\prime}$, e.g., $\mathrm{C}, \mathrm{Al}$ and $\mathrm{Ti}[8,9]$. With an excessive increase in alloying degree, microstructural properties were aggravated owing to the formation of as-cast microstructural defects, for example, coarse $\gamma^{\prime}$ phases (primary $\gamma^{\prime}$ ), $\gamma-\gamma^{\prime}$ eutectic, large carbides and detrimental topologically close-packed phases (TCP) which are unfavorable to the properties of alloy $[10,11]$. As a leading material for large stationary gas turbine in China, Rene 80 is a precipitation-strengthened cast nickelbased superalloy with a relatively high alloying degree.

For most of the cast alloys, heat treatment includes solution treatment and aging treatment [12-14]. The purpose of solution treatment is to homogenize the as-cast microstructure and eliminate the composition segregation, simultaneously dissolve coarse as-cast $\gamma^{\prime}$ particles, $\gamma-\gamma^{\prime}$ eutectic and carbides into the matrix [15]. The role of aging 
treatment is to adjust the size and distribution of secondary $\gamma^{\prime}$ particles and optimize alloy microstructure and properties [16]. The fine secondary $\gamma^{\prime}$ particles are distributed more uniformly than as-cast $\gamma^{\prime}$ particles. In the processes of solid solution and aging treatment, carbides also change correspondingly. Most of primary $M \mathrm{C}$ carbides usually divide into the stable secondary $M_{6} \mathrm{C}$ or $M_{23} \mathrm{C}_{6}$ carbides $[15,17,18]$. These carbide particles play an important role in hindering the migration of grain boundaries and dislocations and thus improve the creep properties of alloy $[9,19]$.

At present, the studies on heat treatment of nickel-based superalloys have gained comprehensive attention [20-24]. However, the various parameters of heat treatment have diverse influences on microstructural evolution and mechanical properties. Safari et al. [12] did some investigations on the heat treatment of Rene 80 , and they considered that the nucleation rate of secondary $\gamma^{\prime}$ precipitates can be improved with increasing cooling rate after aging treatment. For a similar alloy UDIMET 500, Sajjadi et al. [17] held that the size, shape and volume fraction of secondary $\gamma^{\prime}$ particles were deeply impacted by the cooling rate following solid solution treatment, and with increasing cooling rate, the size and volume percent of primary $\gamma^{\prime}$ particles decreased. Moreover, Bhowal et al. [25] also deemed that the size of the secondary $\gamma^{\prime}$ particles depended on the cooling rate after solution treatment. Based on a literature survey, all previous studies focus on the effect of the cooling rate on the solid solution microstructure, but there has little work to be published about the potential effects of the cooling rate on microstructural evolution during subsequent heat treatment and the final microstructures and mechanical properties. It is well known that the parameters of solution treatment not only impact directly the solid solution microstructures and properties, but also have potential influences on the microstructural evolution in subsequent heat treatment. Therefore, this work investigated the influence of the cooling rate after solution treatment on the microstructural evolution and mechanical properties in detail. And the aim is to provide a theoretical basis for designing heat treatment route of the similar chemical composition alloy.

\section{Experimental}

Table 1 lists the chemical composition of the experimental alloy which was produced by $5-\mathrm{kg}$ vacuum induction melting and casting. The alloy was subjected to heat

Table 1 Chemical composition of the alloy (wt \%)

\begin{tabular}{llllllllll}
\hline $\mathrm{C}$ & $\mathrm{Cr}$ & $\mathrm{Co}$ & $\mathrm{W}$ & $\mathrm{Mo}$ & $\mathrm{Al}$ & $\mathrm{Ti}$ & $\mathrm{B}$ & $\mathrm{Zr}$ & $\mathrm{Ni}$ \\
\hline 0.15 & 13.98 & 9.62 & 4.17 & 4.02 & 2.87 & 4.8 & 0.013 & 0.061 & $\mathrm{Bal}$. \\
\hline
\end{tabular}

treatment with the solution treatment followed by three different cooling methods, corresponding to three cooling rates, as shown in Table 2. Cooling rate was measured by using a thermocouple thermometer. The average cooling rate of water cooling (WC), air cooling (AC) and furnace cooling (FC) is about 138,20 and $0.5^{\circ} \mathrm{C} / \mathrm{s}$, respectively.

Microstructural features were examined by optical microscopy (OM), scanning electron microscopy (SEM), transmission electron microscopy (TEM). Precipitates were analyzed by energy-dispersive spectroscopy (EDS) and selected area electron diffraction (SAED). The size and area fraction of carbides and $\gamma^{\prime}$ were measured by using an image analysis software (Image Pro Plus 6.0). At least twenty micrographs from different grains were selected to minimize measurement errors. The specimens were polished and etched with a solution of $10 \mathrm{~g} \mathrm{CuCl}_{2}+50 \mathrm{ml}$ $\mathrm{HCl}+50 \mathrm{ml} \mathrm{C}_{2} \mathrm{H}_{5} \mathrm{OH}$. Films for TEM observation were mechanically grounded to $50 \mu \mathrm{m}$ and thinned by twin-jet electropolishing with a solution of $10 \mathrm{ml} \mathrm{HClO}_{4}+90 \mathrm{ml}$ $\mathrm{C}_{2} \mathrm{H}_{5} \mathrm{OH}$ at $20 \mathrm{~V}$ and $-50{ }^{\circ} \mathrm{C}$.

The hardness of the alloy was measured by Rockwell hardness C (HRC) test at room temperature. The HRC measurements were taken on a Rockwell hardness machine using an indentation load of $140 \mathrm{~kg}$, a $120^{\circ}$ diamond cone and a dwell time of $10 \mathrm{~s}$. Tensile tests were conducted on the alloy at 25 and $870{ }^{\circ} \mathrm{C}$. Smooth cylindrical specimens have an overall length of $70 \mathrm{~mm}$ with gage length and diameter of 25 and $5 \mathrm{~mm}$, respectively.

\section{Result}

\subsection{As-Cast Microstructure}

Figure 1 shows the OM and SEM microstructures of ascast Rene 80. The OM microstructure has obvious dendritic segregation pattern with the average secondary dendrite arm spacing of $93 \mu \mathrm{m}$ (Fig. 1a). It reveals that as-cast microstructure consists of matrix phase $\gamma$, strengthening phase $\gamma^{\prime}$, a limited amount of $\gamma^{\prime}-\gamma$ eutectic and carbides (Fig. 1b, c). The $\gamma^{\prime}-\gamma$ eutectics with petal-like morphology, which were solidified as the last parts of the liquid during solidification, were distributed in interdendritic regions while the blocky or script morphology carbides existed both on grain boundaries and within grains (Fig. 1b, d). The $\gamma^{\prime}$ average area fraction is as high as $48.3 \%$ with the average size of $0.55 \pm 45 \mu \mathrm{m}$. In addition, it is evidently found that the size of $\gamma^{\prime}$ particles in interdendritic regions is larger than that in the dendrite cores (Fig. 1d). Figure 1e gives the EDS result of carbide composition in as-cast microstructures, indicating that it is Ti-rich $M \mathrm{C}$ carbide (where $M$ represents metal ion and $\mathrm{C}$ represents carbon atom). 
Table 2 Heat treatment schedule

\begin{tabular}{lll}
\hline Sample code & Solution & Aging \\
\hline WC & $1200{ }^{\circ} \mathrm{C} / 2 \mathrm{~h} / \mathrm{WC}$ & $1095{ }^{\circ} \mathrm{C} / 4 \mathrm{~h} / \mathrm{AC}+$ \\
& & $1080^{\circ} \mathrm{C} / 4 \mathrm{~h} / \mathrm{AC}$ \\
& $+870{ }^{\circ} \mathrm{C} / 12 \mathrm{~h} / \mathrm{AC}$ \\
AC & $1200{ }^{\circ} \mathrm{C} / 2 \mathrm{~h} / \mathrm{AC}$ & \\
FC & $1200{ }^{\circ} \mathrm{C} / 2 \mathrm{~h} / \mathrm{FC}$ & \\
\hline
\end{tabular}

\subsection{Microstructural Characteristics After Solution Treatment}

Figure 2 shows a typical full solution treatment after solution treatment at $1200{ }^{\circ} \mathrm{C}$ for $2 \mathrm{~h}$ with different cooling methods of WC, AC and FC. As shown in Fig. 2a-c, there are some common microstructural changes in $\mathrm{WC}, \mathrm{AC}$ and FC samples described as follows: Firstly, original coarse $\gamma^{\prime}$ precipitates in as-cast state completely dissolve since the solvus temperature for $\gamma^{\prime}$ is about $1150{ }^{\circ} \mathrm{C}$ in this alloy [15]; secondly, composition segregation is almost eliminated and thus microstructure uniformity is improved; thirdly, the average size of carbides slightly decreases from 6.7 to $4.9 \mu \mathrm{m}$ without change in the crystallographic structure. A purpose of the solution treatment is to fully dissolve coarse $\gamma^{\prime}$ precipitates and large carbides into the matrix and obtain supersaturated solution matrix for fine strengthening phase precipitating during subsequent aging treatment. Figure $2 \mathrm{~d}$ exhibits that there are a few minimal $\gamma^{\prime}$ particles in WC sample with the highest cooling rate. However, Fig. 2e and f shows that abundant and fine $\gamma^{\prime}$ particles (secondary $\gamma^{\prime}$ ) re-precipitate in AC and FC samples. The average size of secondary $\gamma^{\prime}$ in AC and FC samples is about 70 and $226 \mathrm{~nm}$, respectively.

\subsection{Microstructural Characteristics at Different Aging Stages}

To study the potential effects of the cooling rate after solution treatment on the microstructural evolution in subsequent heat treatment, aging treatment at $1095{ }^{\circ} \mathrm{C} /$ $4 \mathrm{~h} / \mathrm{AC}+1080{ }^{\circ} \mathrm{C} / 4 \mathrm{~h} / \mathrm{AC}+870{ }^{\circ} \mathrm{C} / 12 \mathrm{~h} / \mathrm{AC}$ was performed on WC, AC and FC samples. Figure 3a-i shows the microstructural evolution in three samples after each aging step. It seems that the micrograph of secondary $\gamma^{\prime}$ transforms from approximately spherical (ellipsoidal) into cubic; moreover, the $\gamma^{\prime}$ size significantly increases. Higher magnification figures show that the microstructure consists of secondary $\gamma^{\prime}$ particles and a mass of hyperfine tertiary $\gamma^{\prime}$ particles (about $58 \mathrm{~nm}$ ) which are believed to form during cooling period, as marked by the arrows in Fig. 3. Nevertheless, the amount of tertiary $\gamma^{\prime}$ particles reduces after aging treatment at $870{ }^{\circ} \mathrm{C} / 12 \mathrm{~h} / \mathrm{AC}$, especially those nearby secondary $\gamma^{\prime}$ particles, as shown in Fig. 3g-i. This is due to the secondary $\gamma^{\prime}$ coarsening in a mode of absorbing tertiary $\gamma^{\prime}$ particles [12]. Table 3 provides the statistical data of secondary $\gamma^{\prime}$ precipitates at different aging treatment stages. It indicates that the $\gamma^{\prime}$ average size in WC, AC and FC samples increases gradually from 295 to $388 \mathrm{~nm}$, from 290 to $402 \mathrm{~nm}$ and from 316 to $395 \mathrm{~nm}$, respectively. The $\gamma^{\prime}$ area fraction increases, respectively, to $24.7,29.2$ and $26.5 \%$, showing that three samples almost achieve a close value after the whole heat treatment.

\subsection{Evolution of the Carbides and Grain Boundaries}

Carbides and grain boundaries in three samples have similar changes during the heat treatment. As an example, the changes of AC sample are exhibited here. Figure $4 a, b$ reveals that after the high-temperature aging of $1095{ }^{\circ} \mathrm{C} /$ $4 \mathrm{~h} / \mathrm{AC}+1080{ }^{\circ} \mathrm{C} / 4 \mathrm{~h} / \mathrm{AC}$, the morphology and size of carbides do not obviously change compared with solid solution sample. These carbides distribute on grain boundaries or in grain interiors. In addition, according to EDS analysis, it is suggested that the type of carbides does not change and it is identified to be the Ti-rich MC carbides. However, it is noted that carbides are decomposed during low-temperature aging at $870{ }^{\circ} \mathrm{C} / 12$ h/AC. Furthermore, two kinds of bright precipitates around primary $M C$ carbides in the grain as marked in Fig. 4c are significantly observed by backscattered scanning electron morphology (BS-SEM). Moreover, the EDS results (Table 4) reveal that the phases are rich in $\mathrm{Mo}, \mathrm{W}$ and $\mathrm{Cr}$. Furthermore, according to the selected area electron diffraction pattern (SAED) (Fig. 5a), it is determined that the lattice parameter, $a_{0}$, of Mo-rich carbides is $1.13 \mathrm{~nm}$ coinciding with that of $M_{6} \mathrm{C}$ carbides [26]. This is also confirmed by TEM observation (Fig. 5a). It is clear to observe another fine and black precipitates around $M C$ carbide on the grain boundary (Fig. 5b), and EDS data (Table 4) reveal that the phase is rich in $\mathrm{Cr}$. In addition, the SAED confirms that the lattice parameter $\left(a_{0}=1.06 \mathrm{~nm}\right)$ of $\mathrm{Cr}$-rich carbides coincides with that of $M_{23} \mathrm{C}_{6}$ carbides [27]. Thus, from the above results, the primary $M C$ starts to be decomposed into $M_{6} \mathrm{C}$ or $M_{23} \mathrm{C}_{6}$ during the low-temperature aging.

Figure $6 \mathrm{a}$ together with Fig. $4 \mathrm{a}-\mathrm{c}$ show that the morphology of grain boundaries almost keeps serrated and decorated with carbides and $\gamma^{\prime}$ precipitates in the whole process of heat treatment [28, 29]. Additionally, it is interesting to find that the $\gamma^{\prime}$ precipitates on the local grain boundary aggregate and coarsen with $\gamma^{\prime}$ depleting on both sides of grain boundary (Fig. 6b). 

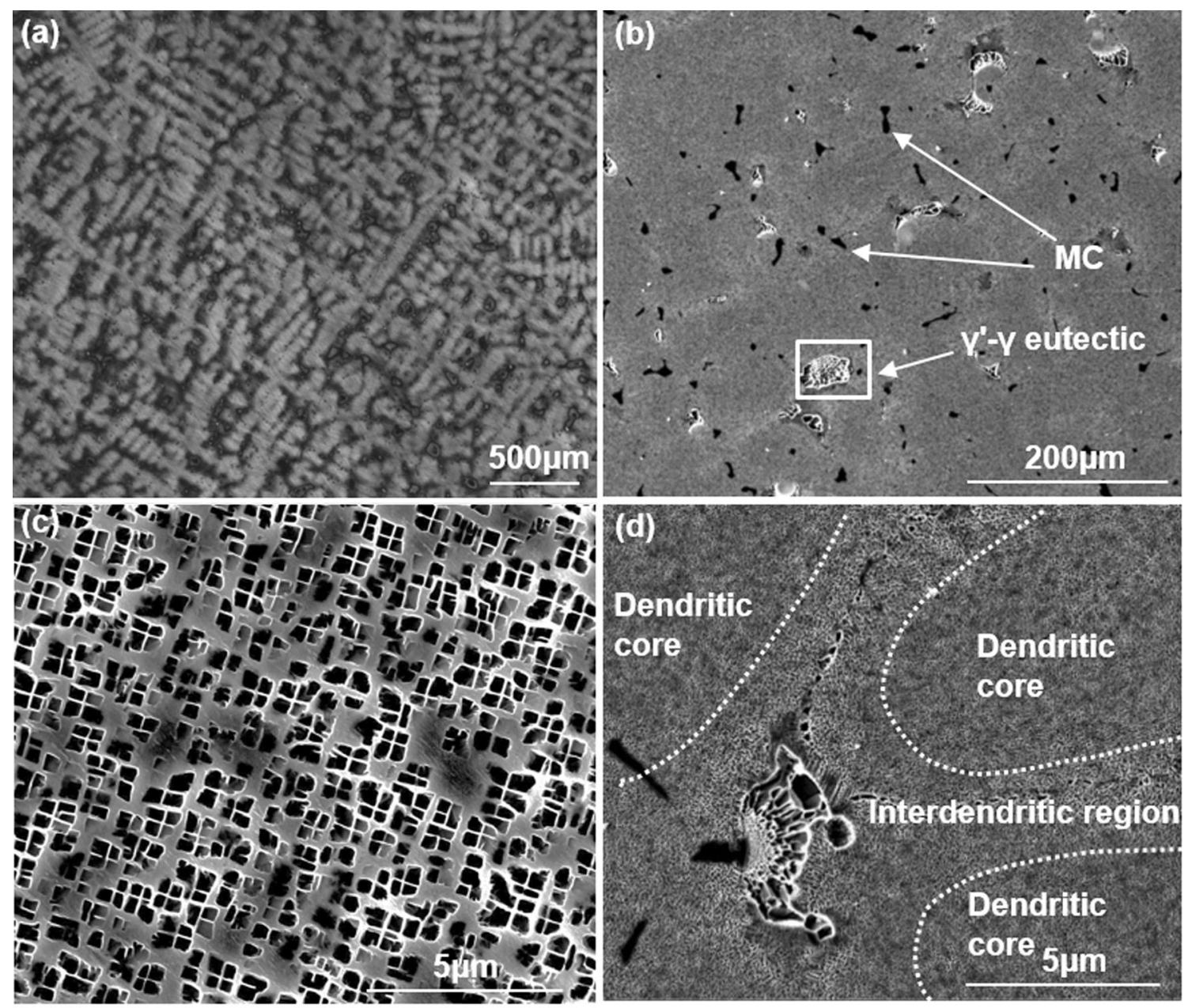

(e)

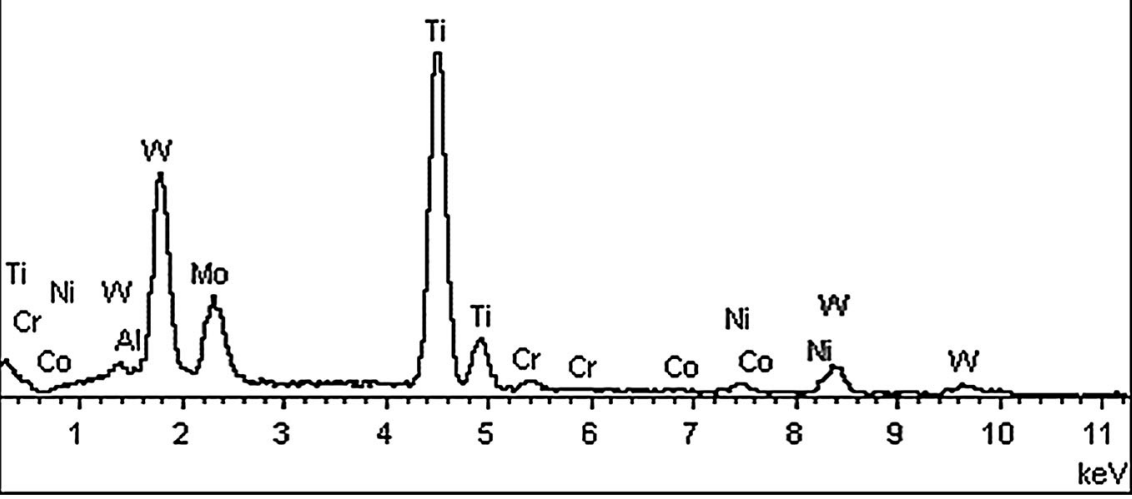

Fig. 1 Microstructures of the as-cast experimental alloy and EDS analysis: a OM image showing the dendritic microstructure; b SEM micrograph showing $M C$ carbides morphology in as-cast microstructure; c morphology of $\gamma^{\prime}$ precipitates; d SEM micrograph showing $\gamma-\gamma^{\prime}$ eutectic in detail; e EDS spectrum of Ti-rich $M C$ carbide 

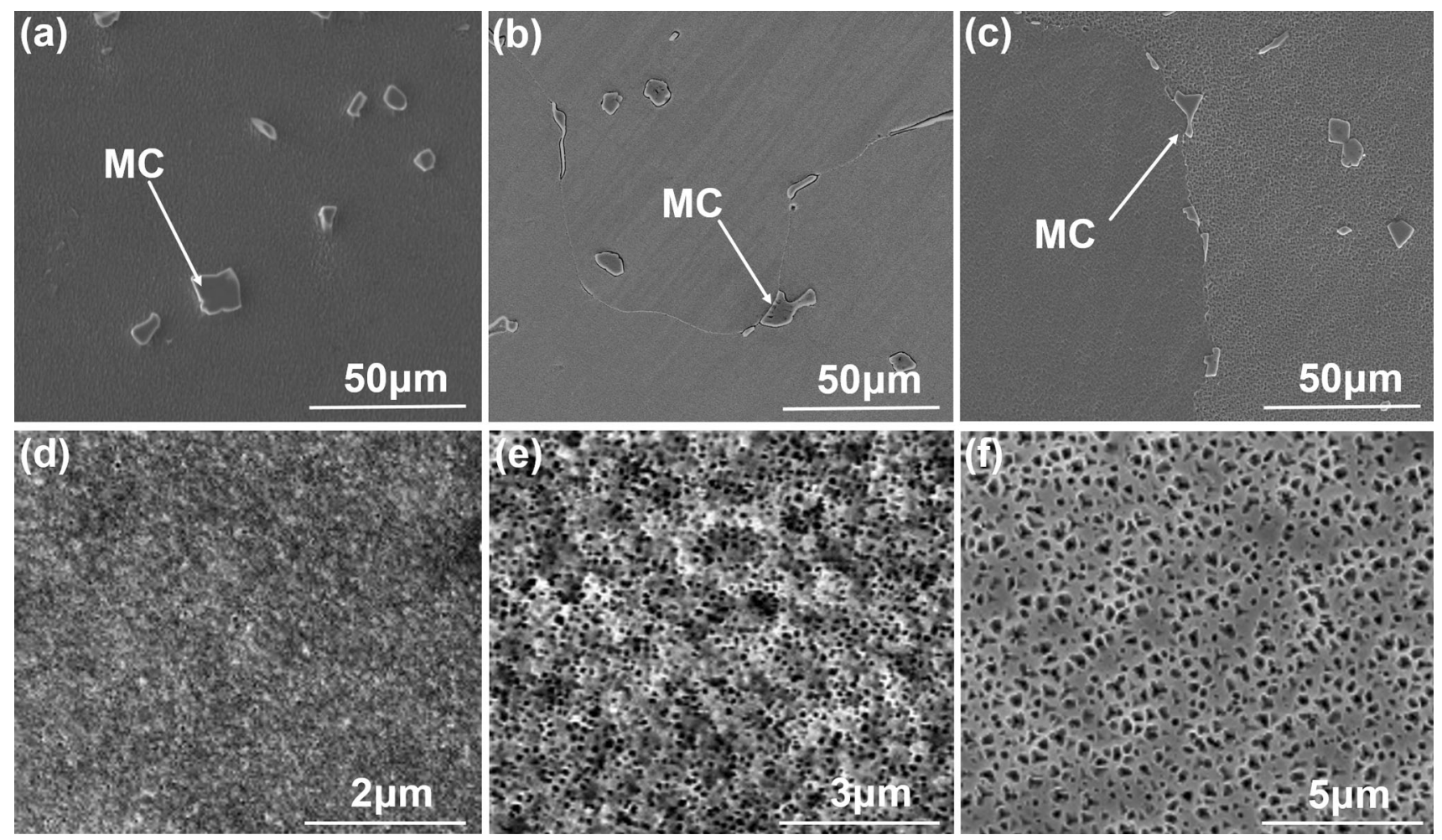

Fig. 2 Effects of the cooling methods after solution treatment on the microstructures: a-c microstructures of WC, AC and FC samples, respectively, $\mathbf{d}-\mathbf{f}$ corresponding $\gamma^{\prime}$ image of WC, AC and FC samples, respectively

\section{Discussion}

\subsection{As-Cast Microstructure and Solution Microstructure}

Rene 80 is a $\gamma^{\prime}$ strengthening-type alloy with a high alloying degree. The addition of alloying elements causes serious dendritic segregation in as-cast microstructure (Fig. 1a). In the process of solidification, refractory elements segregate to the dendritic core, such as $\mathrm{W}$ and Mo, while some elements with low melting point segregate to the interdendritic region, such as $\mathrm{Al}$ and Ti which are $\gamma^{\prime}$ formation elements [30]. The enrichment of $\mathrm{Al}$ and $\mathrm{Ti}$ in the interdendritic region promotes $\gamma^{\prime}$ growth and $\gamma^{\prime}-\gamma$ eutectic formation. This is the reason why the size of $\gamma^{\prime}$ particles in the interdendritic region is significantly larger than that in the dendritic cores (Fig. 1d). In addition, $\gamma^{\prime}-\gamma$ eutectic, which forms at the end of solidification, is enriched in low melting point alloy elements. The existence of $\gamma^{\prime}-\gamma$ eutectic is detrimental to high-temperature properties of nickel-based superalloys.

After solution treatment at $1200{ }^{\circ} \mathrm{C} / 2 \mathrm{~h}$, the alloy has a typical full-solution-treatment microstructure with fine secondary $\gamma^{\prime}$ particles and small carbides. During the cooling process after solution treatment, the cooling rate has noticeable influence on secondary $\gamma^{\prime}$ size in supersaturated microstructure, as shown in Fig. 2. It reveals that the $\gamma^{\prime}$ size increases with the decrease in cooling rate. It is well known that the driving force of phase transformation is the free energy change, $\Delta G$, before and after phase transformation. Additionally, $\Delta G$ can be expressed as a function of the supercooling degree, $\Delta T$, which has a directly proportional relationship with cooling rate, following the formula $\Delta G=\Delta H \cdot \Delta T / T$ [31], where $\Delta H$ is the latent heat of phase transformation which is a positive value for $\gamma^{\prime}$ phase transformation. It indicates that there is a directly proportional relationship between $\Delta G$ and $\Delta T$. In consequence, a fast cooling rate contributes to rapid nucleating of $\gamma^{\prime}$ particles, but inhibits growth of $\gamma^{\prime}$ particles, as shown in Fig. 2b, which shows denser and smaller $\gamma^{\prime}$ particles in AC sample compared with that in FC sample. However, when cooling rate is dramatically rapid, solute atoms diffusion capacity is limited to form the $\gamma^{\prime}$ particles during cooling process, as illustrated in WC sample which consists of rare $\gamma^{\prime}$ particles (Fig. 2a). When cooling rate is excessively slow, a small supercooling degree leads to a low $\gamma^{\prime}$ nucleation rate, but promotes the growth of $\gamma^{\prime}$ particles since there is enough time for solute atoms to diffuse sufficiently during the cooling process. As shown in Fig. 2c, the average size of secondary $\gamma^{\prime}$ particles in FC sample is larger, but the density is lower. 

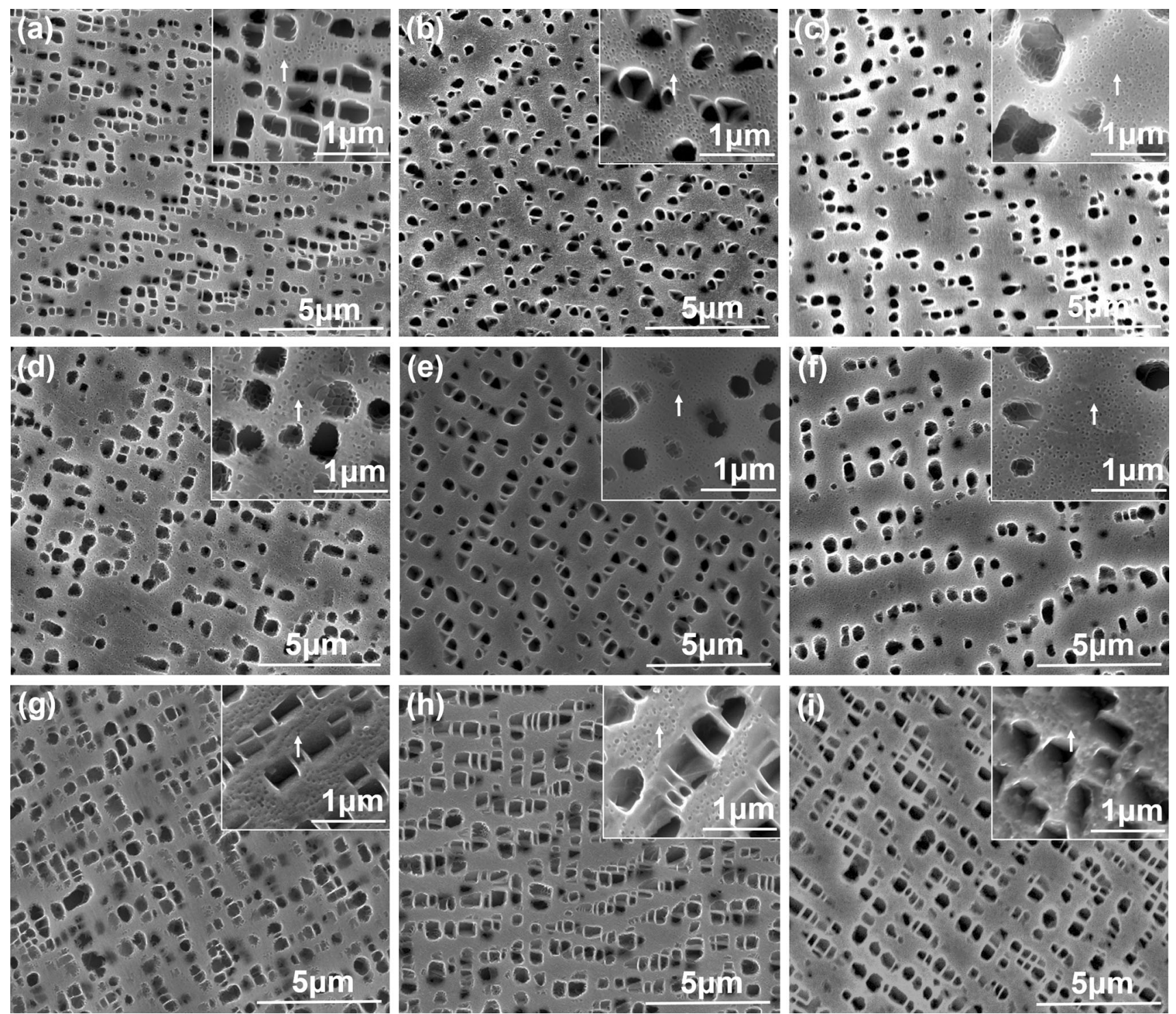

Fig. 3 SEM micrographs of $\gamma^{\prime}$ precipitates in three samples at different aging heat treatment stages: a-c at $1095{ }^{\circ} \mathrm{C} / 4 \mathrm{~h} / \mathrm{AC} ; \mathbf{d}-\mathbf{f}$ at $1080{ }^{\circ} \mathrm{C} / 4 \mathrm{~h} /$ $\mathrm{AC} ; \mathbf{g}-\mathbf{i}$ at $870{ }^{\circ} \mathrm{C} / 12 \mathrm{~h} / \mathrm{AC}$. Insets in upper right show hyperfine tertiary $\gamma^{\prime}$ particles in the matrix as marked by the arrows

Table 3 Statistical size and area fraction of secondary $\gamma^{\prime}$ precipitates at different aging heat treatment stages

\begin{tabular}{|c|c|c|c|c|c|c|}
\hline \multirow[t]{2}{*}{ Heat treatment stage } & \multicolumn{2}{|l|}{ WC } & \multicolumn{2}{|l|}{$\mathrm{AC}$} & \multicolumn{2}{|l|}{$\mathrm{FC}$} \\
\hline & $d(\mathrm{~nm})$ & Area fraction $(\%)$ & $d(\mathrm{~nm})$ & Area fraction $(\%)$ & $d(\mathrm{~nm})$ & Area fraction $(\%)$ \\
\hline 1 & $295 \pm 24$ & 15.7 & $290 \pm 34$ & 16.5 & $316 \pm 54$ & 14.7 \\
\hline 2 & $345 \pm 46$ & 19.8 & $355 \pm 51$ & 17.8 & $372 \pm 35$ & 15.9 \\
\hline 3 & $391 \pm 36$ & 24.7 & $402 \pm 21$ & 29.2 & $415 \pm 24$ & 26.5 \\
\hline
\end{tabular}

1-Aging heat treatment at $1095{ }^{\circ} \mathrm{C} / 4 \mathrm{~h} / \mathrm{AC} ; 2$-aging heat treatment at $1080{ }^{\circ} \mathrm{C} / 4 \mathrm{~h} / \mathrm{AC} ; 3$-aging heat treatment at $870{ }^{\circ} \mathrm{C} / 12 \mathrm{~h} / \mathrm{AC}$

\subsection{Microstructural Evolution}

During the aging treatment below $\gamma^{\prime}$ solvus temperature, secondary $\gamma^{\prime}$ precipitates will nucleate and grow up. The morphology and size of $\gamma^{\prime}$ precipitates change significantly with extending holding time. As shown in Fig. 3, the morphology of secondary $\gamma^{\prime}$ precipitates in three specimens transforms from circular into cubic. This indicates that the 

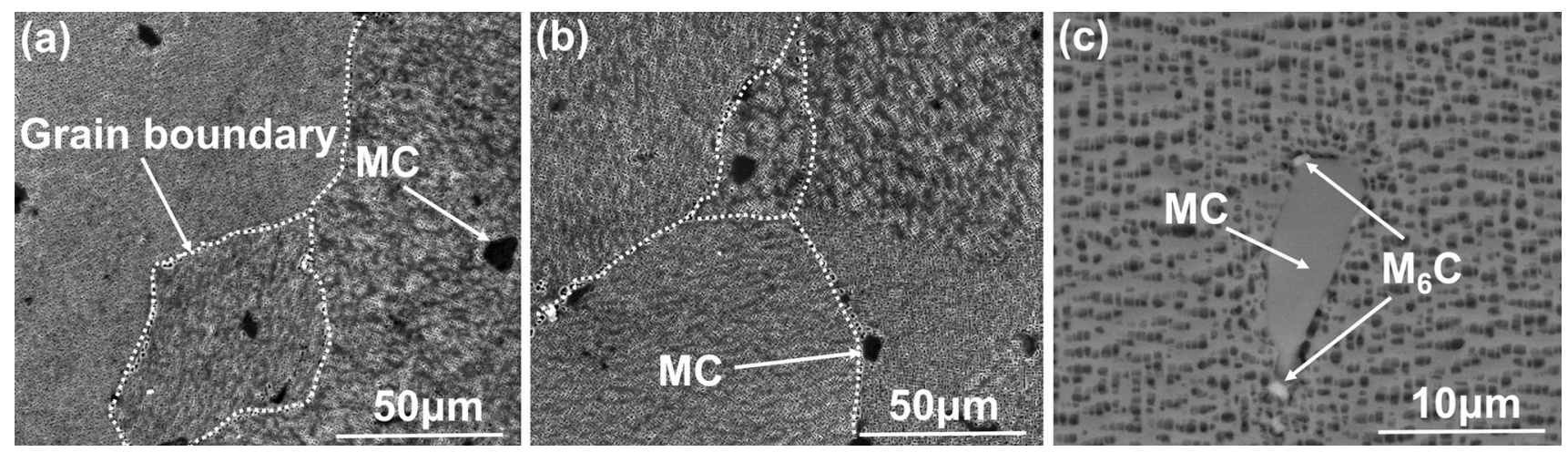

Fig. 4 SEM microstructures of the carbides and grain boundaries (marked by dotted lines) of AC sample in different heat treatment stages of a $1095{ }^{\circ} \mathrm{C} / 4 \mathrm{~h} / \mathrm{AC}, \mathbf{b} 1080{ }^{\circ} \mathrm{C} / 4 \mathrm{~h} / \mathrm{AC}$, c BS-SEM microstructure after aging of $870{ }^{\circ} \mathrm{C} / 12 \mathrm{~h} / \mathrm{AC}$

Table 4 EDS analysis of different carbides

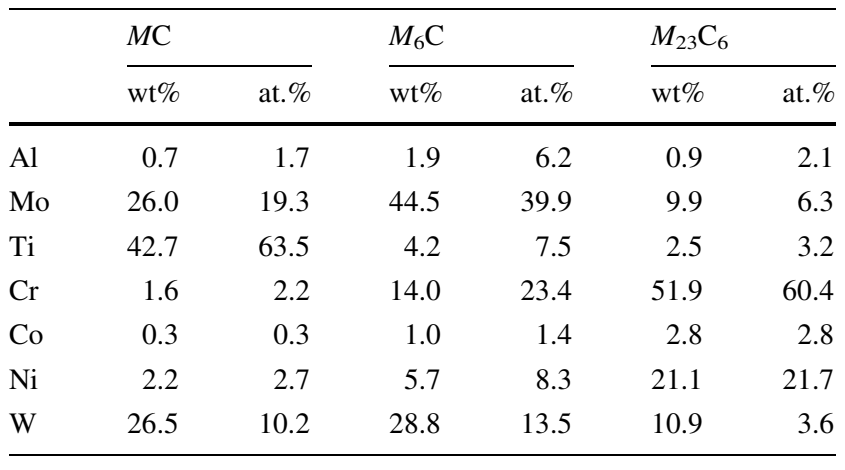

cooling rate after solution treatment has no effects on the morphology change in secondary $\gamma^{\prime}$ precipitates. In addition, the secondary $\gamma^{\prime}$ precipitates noticeably coarsen. It is generally accepted that the process of secondary $\gamma^{\prime}$ coarsening obeys the Lifshitz-Slyozov-Wagner theory (LSW), which means that the coarsening is controlled by diffusion [32]. Therefore, the coarsening of secondary $\gamma^{\prime}$ is described by the cube rate law [33]:

$r^{3}-r_{0}^{3}=K t$,

where $r$ is the secondary $\gamma^{\prime}$ average size after aging time t. $r_{0}$ is the initial average size at the beginning of coarsening process and, $K$ is defined as the secondary $\gamma^{\prime}$ growth rate.

The value of $K$ is measured by Formula (1) on the basis of statistical data of secondary $\gamma^{\prime}$ precipitates at different aging stages (Table 3 ). In order to analyze the impact of cooling rate after solution treatment, the relationship between secondary $\gamma^{\prime}$ growth rate and cooling rate after solution treatment is shown in Fig. 7. It is obvious to find that cooling rate has potential influences on $K$ during different aging stages. The secondary $\gamma^{\prime}$ of WC and AC sample has a similar $\gamma^{\prime}$ growth rate which is higher than that in FC sample at aging of $1095{ }^{\circ} \mathrm{C} / 4 \mathrm{~h} / \mathrm{AC}$. This is attributed to the formation of larger initial $\gamma^{\prime}$ precipitates in
FC sample which leads to the consumption of massive formation elements and the decrease in supersaturation degree in solution microstructure. In most of superalloys, $\mathrm{Al}$ and $\mathrm{Ti}$ are the main formation elements of $\gamma^{\prime}$, which exist as substitution atoms in $\gamma$ channel. As shown in schematic diagram (Fig. 8) without the consideration of lattice distortion, the amount of $\mathrm{Al}$ and $\mathrm{Ti}$ around smaller $\gamma^{\prime}$ precipitates is more than that around larger $\gamma^{\prime}$ precipitates. Accordingly, the amount of formation elements diffusing into larger $\gamma^{\prime}$ precipitates is less than that into smaller $\gamma^{\prime}$ during the same time. As a result, the growth rate of large secondary $\gamma^{\prime}$ during aging treatment is lower than that of small secondary $\gamma^{\prime}$. However, the growth rates of secondary $\gamma^{\prime}$ in different samples are very close during aging treatment at $1080{ }^{\circ} \mathrm{C} / 4 \mathrm{~h} / \mathrm{AC}$ and $870{ }^{\circ} \mathrm{C} / 12 \mathrm{~h} / \mathrm{AC}$, which is because the saturation of formation elements in all specimens reduces to a similar degree after previous aging treatment. And the statistical data in Table 3 also demonstrate that microstructural features have no significant difference after aging of $1080{ }^{\circ} \mathrm{C} / 4 \mathrm{~h} / \mathrm{AC}$ and $870{ }^{\circ} \mathrm{C} / 12 \mathrm{~h} /$ AC. In addition, lower temperature contributes to the decrease in atom diffusing capability in the matrix. As a result, the $\gamma^{\prime}$ growth rate at $870{ }^{\circ} \mathrm{C} / 12 \mathrm{~h} / \mathrm{AC}$ is lower compared to that at $1095{ }^{\circ} \mathrm{C} / 4 \mathrm{~h} / \mathrm{AC}$. This indicates that $K$ value is primarily dependent on temperature.

It is interesting to find from Table 4 that the $\gamma^{\prime}$ area fraction is increased by $63.5 \%$ during the aging at $870{ }^{\circ} \mathrm{C} /$ $12 \mathrm{~h} / \mathrm{AC}$, but the $\gamma^{\prime}$ average size is merely enhanced by $6.2 \%$ in FC sample. As shown in Fig. 3, fine $\gamma^{\prime}$ obviously grows up while large $\gamma^{\prime}$ precipitates almost remain unchanged during low-temperature aging. This indicates that the growth of fine $\gamma^{\prime}$ precipitates predominantly leads to the increase in $\gamma^{\prime}$ area fraction. The result is consistent with the report [21], which illustrates a conclusion that low aging temperature can suppress the growth of coarse $\gamma^{\prime}$ precipitates, but promote the growth of fine $\gamma^{\prime}$ precipitates. Furthermore, it is found that both the size and the area fraction of $\gamma^{\prime}$ particles in AC sample increase slightly 

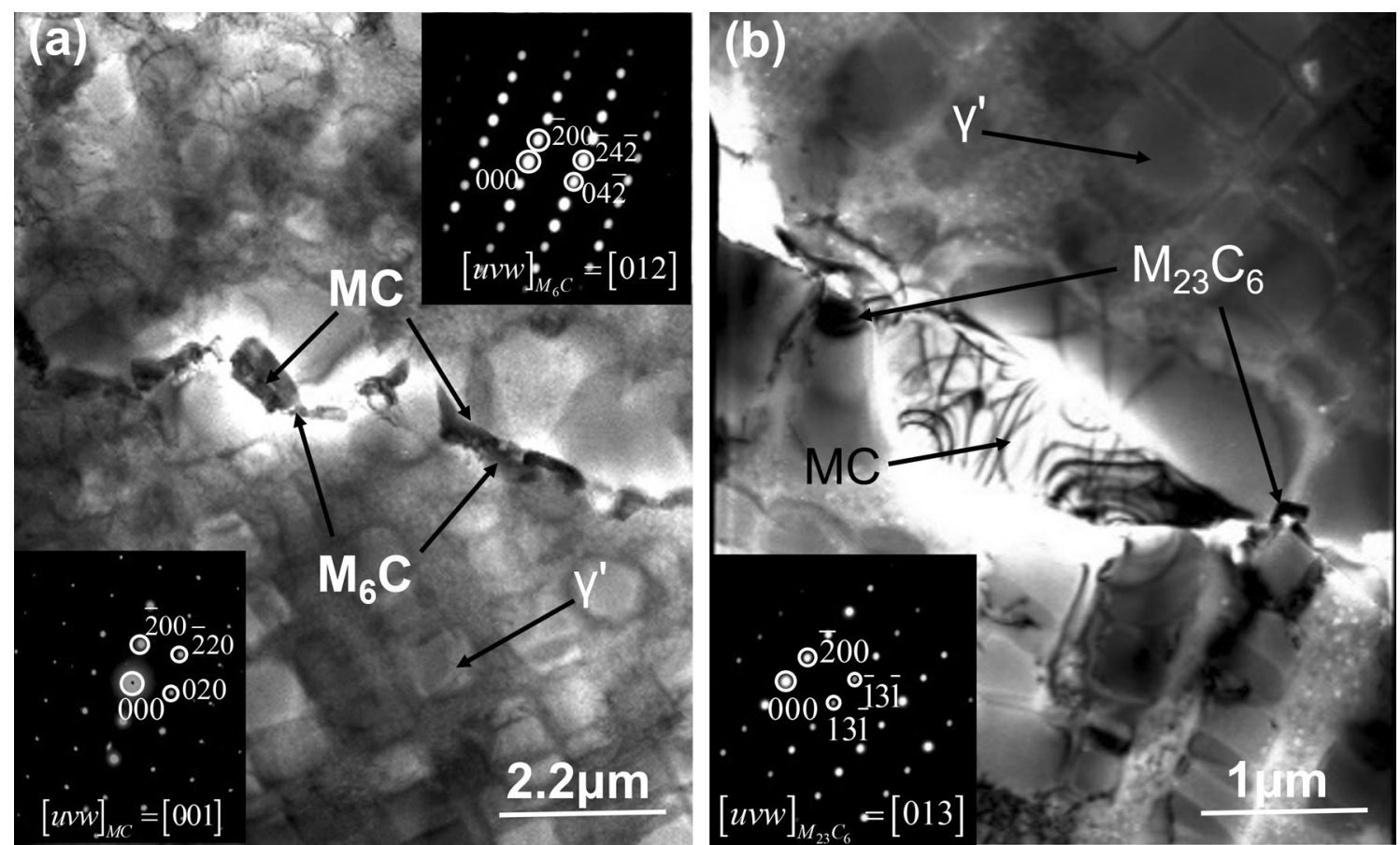

Fig. 5 TEM microstructures and SAED patterns of the carbides on grain boundaries of $\mathrm{AC}$ sample at $870{ }^{\circ} \mathrm{C} / 12 \mathrm{~h} / \mathrm{AC}$ aging: a $M_{6} \mathrm{C}$ topography, $M_{6} \mathrm{C}$ SAED pattern (inset in upper right corner) and $M C$ SAED pattern (inset in lower left corner); $\mathbf{b}_{23} \mathrm{C}_{6}$ topography and $M_{23} \mathrm{C}_{6} \mathrm{SAED}$ pattern (inset)
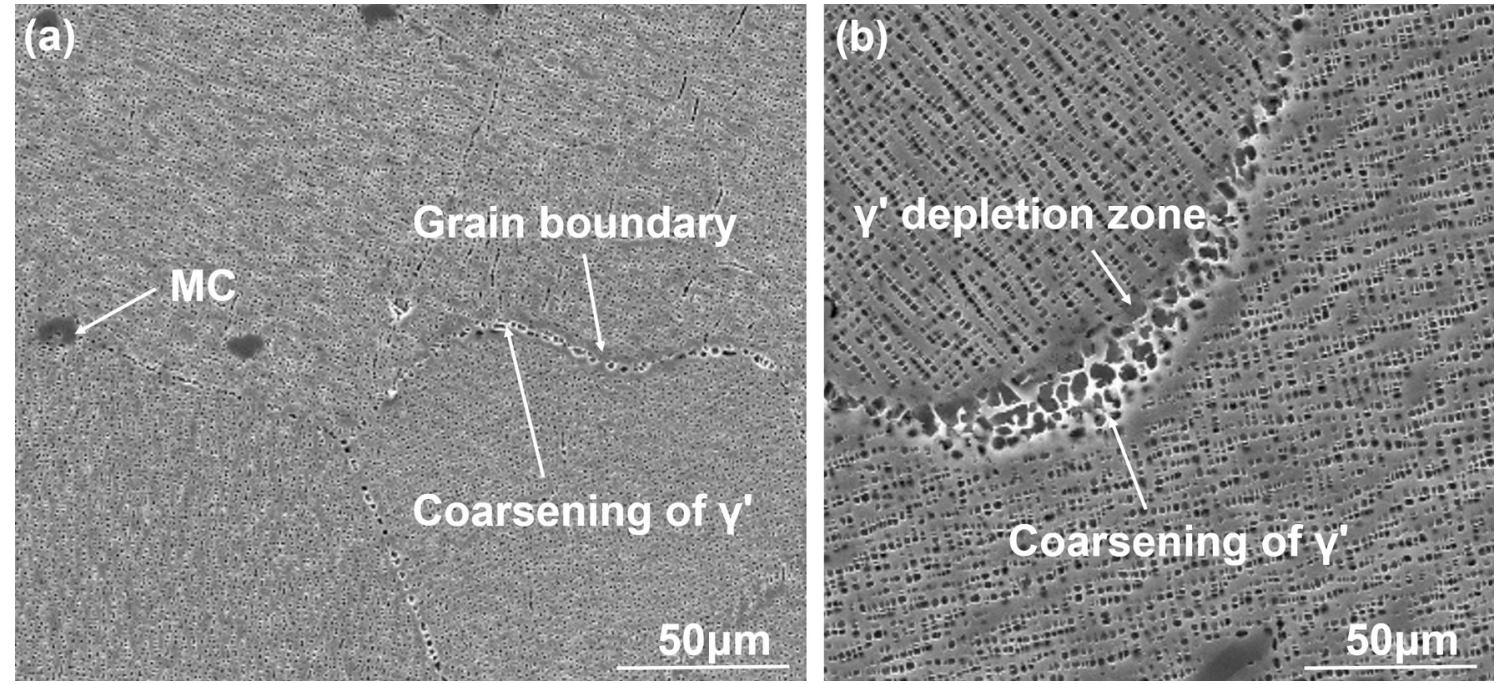

Fig. 6 SEM images: a $\gamma^{\prime}$ coarsening on grain boundary and $\gamma^{\prime}$ depleting on both sides of grain boundary after $870{ }^{\circ} \mathrm{C} / 12 \mathrm{~h} / \mathrm{AC}$, b corresponding higher magnification image

comparing to those of WC and FC samples after long-term aging treatment (Table 3). Because the holding time of low-temperature aging is long enough, the size and area fraction of $\gamma^{\prime}$ phases will reach the constant values to keep concentration stable at a given aging temperature. Therefore, it is concluded that the cooling rate after solution treatment has striking influences on the microstructural evolution in subsequent heat treatment, but has no noticeable effects on microstructural features after the overall heat treatment.

\subsection{Evolution of Carbides and Grain Boundaries}

The as-cast Rene 80 microstructures consist of a lot of primary $M C$ carbides (Fig. 1b) which are the most stable carbides [21]. During solution treatment and high- 


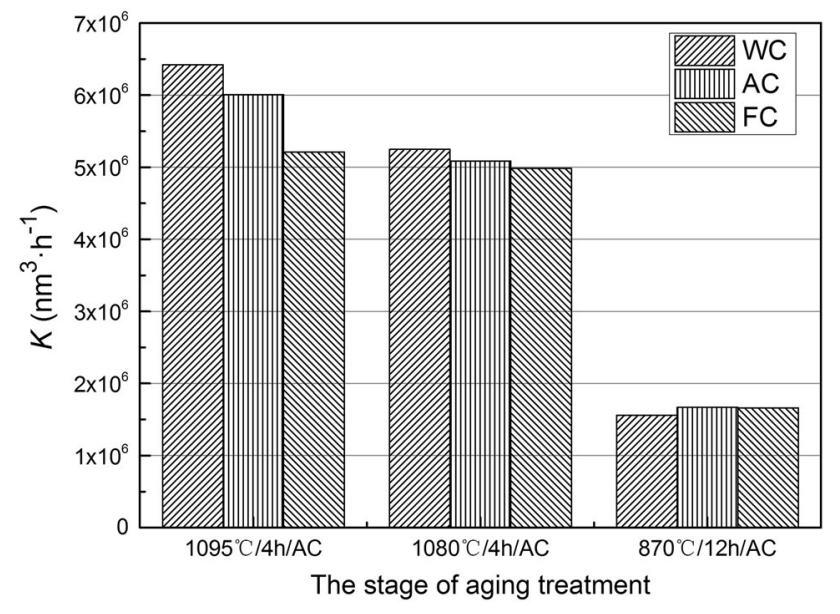

Fig. 7 Growth rate $(K)$ of $\gamma^{\prime}$ particles of three samples during the aging treatment

temperature aging treatment, the $M C$ size slightly reduces without decomposition mainly because the holding time remained relatively short. But during low and long temperature aging, the $M C$ carbides start to decompose into relatively stable $M_{6} \mathrm{C}$ or $M_{23} \mathrm{C}_{6}$ carbides (Figs. $4 \mathrm{c}, 5$ ) because $M C$ is chronically kept in thermodynamic instability state. Due to a long holding time, $\mathrm{C}$ atoms have enough time to diffuse and react with other metal elements, such as $\mathrm{Cr}$ or Mo. The carbide reaction is as follows: $M C+\gamma \rightarrow M_{6} \mathrm{C}$ or $M_{23} \mathrm{C}_{6}+\gamma^{\prime}[8,15]$. Discrete carbides distributed within grains hinder dislocation moving, and those on grain boundaries prevent the grain boundary moving during high-temperature creep deformation. Therefore, both help to improve high-temperature creep properties.

During low-temperature aging, it is found that $\gamma^{\prime}$ phases on local grain boundaries aggregate and coarsen with $\gamma^{\prime}$ phases depleting on both sides of grain boundary (Fig. 6). In general, it is considered that $\gamma^{\prime}$ depletion is a result of carbides or TCP phases formation at the cost of $\gamma^{\prime}$ formation elements [9, 20], but Fig. 6 shows that no carbides and TCP phases exist near $\gamma^{\prime}$ depletion zone, while it shows that

$\gamma^{\prime}$ particles on the grain boundaries coarsen obviously. Hence, during aging treatment, the fine $\gamma^{\prime}$ particles on both sides of grain boundaries have the tendency to diffuse to grain boundaries resulting in the coarsening of $\gamma^{\prime}$ particles on grain boundaries. It is well known that grain boundaries are important planar defects with high energy and stay in an unstable state. It indicates that the $\gamma^{\prime}$ particles movement contributes to decrease the energy of grain boundary, which keeps the alloy system at a low energy status and ensures the alloy system more stable.

\subsection{Mechanical Properties of Finally Gained Microstructure}

In order to examine the effect of the cooling rate after solution treatment on the mechanical properties, doublespecimen hard tests and tensile tests were performed at 25 and $870{ }^{\circ} \mathrm{C}$, respectively. Table 5 gives the data of yield strength (YS), ultimate tensile strength (UTS), elongation (El) and reduction of area percentage (RA) of WC, AC and FC samples. Each value represents the average value of two repetitions. Generally, the material properties are closely related to microstructural features. The comparison of the hardness and tensile results at $25{ }^{\circ} \mathrm{C}$ of three samples indicates that the cooling rate has no influences on the room temperature properties of Rene 80 after the whole heat treatment. These results are coincident with the analysis of the above microstructural evolution. However, the comparison of YS and UTS at $870{ }^{\circ} \mathrm{C}$ between AC and FC samples shows that YS and UTS of AC sample is, respectively, elevated by 7.3 and $14.8 \%$, because the size and area fraction of $\gamma^{\prime}$ particles in AC sample are a little larger than those in FC sample (Table 3). The El and RA values of AC sample slightly decrease compared with FC sample. Nevertheless, there is an unexpected trouble that the tensile data of WC sample are not gained even by three tensile repetitions. These samples straightway rupture before yield stage when they are tested at 25 and $870{ }^{\circ} \mathrm{C}$. With regard to the SEM observation of fractured surfaces

(a)

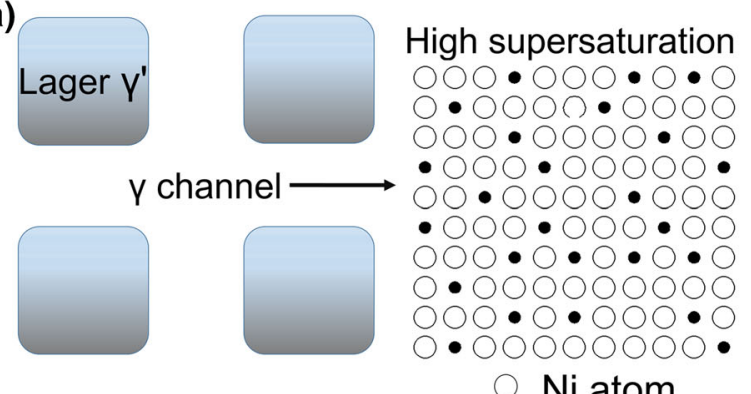

(b)

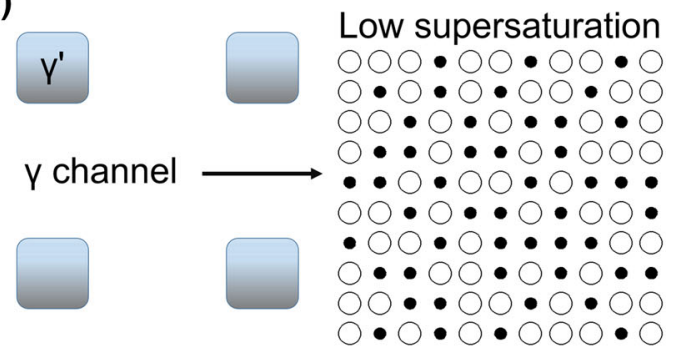

- Al or Ti atom

Fig. 8 Schematic model of solute atom diffusing with different supersaturation degrees: a high supersaturation degree, b low supersaturation degree 
Table 5 Results of mechanical tests for three kinds of samples

\begin{tabular}{|c|c|c|c|c|c|c|c|c|c|}
\hline \multirow[t]{2}{*}{ Sample code } & \multicolumn{4}{|c|}{ Tensile test at $25^{\circ} \mathrm{C}$} & \multicolumn{4}{|c|}{ Tensile test at $870{ }^{\circ} \mathrm{C}$} & \multirow[t]{2}{*}{ Hardness (HRC) } \\
\hline & YS (MPa) & UTS (MPa) & $\mathrm{El}(\%)$ & RA $(\%)$ & YS (MPa) & UTS (MPa) & $\mathrm{El}(\%)$ & $\mathrm{RA}(\%)$ & \\
\hline WC & - & 520.5 & - & - & - & 337.5 & - & - & 41.39 \\
\hline $\mathrm{AC}$ & 938 & 1108 & 6.1 & 8.2 & 585 & 795 & 18.7 & 29 & 41.49 \\
\hline $\mathrm{FC}$ & 937.5 & 1092 & 6.3 & 8 & 545 & 692.5 & 21 & 32.25 & 41.51 \\
\hline
\end{tabular}
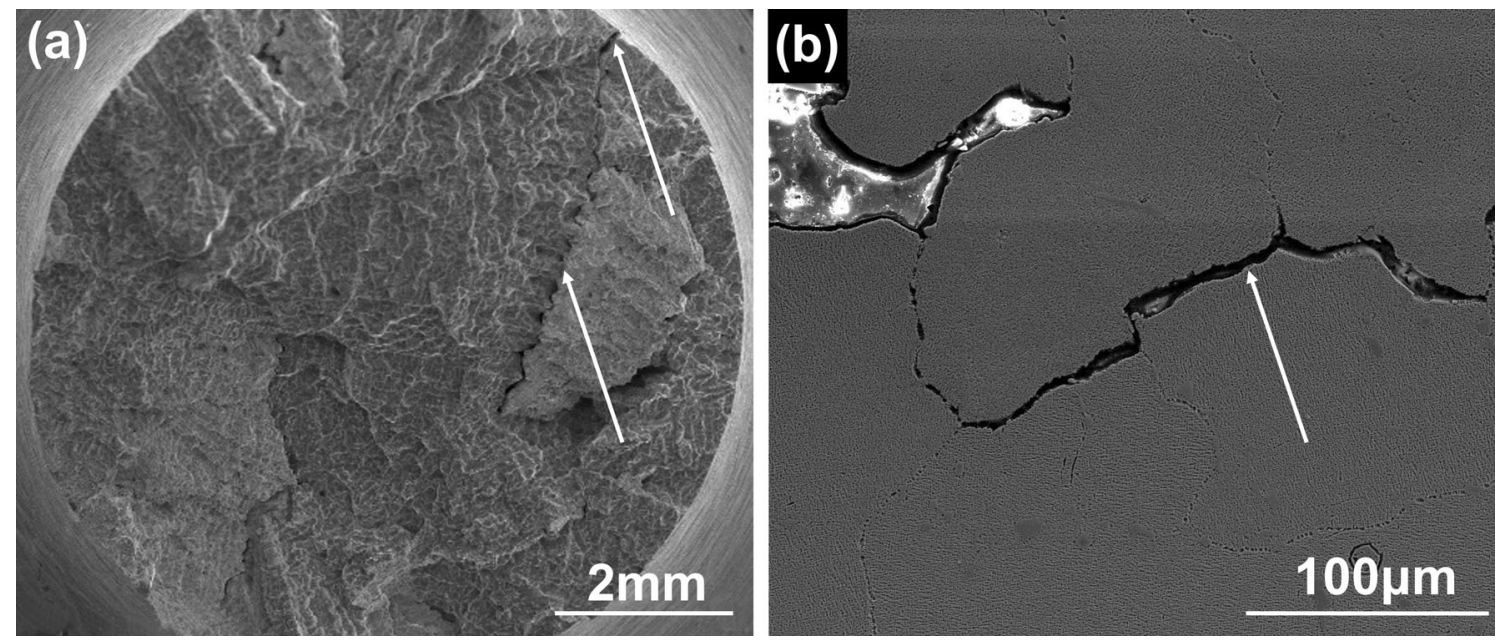

Fig. 9 Intergranular cracks as marked by the arrows in SEM micrographs of fractured surface: a longitudinal section, $\mathbf{b}$ WC sample at $25{ }^{\circ} \mathrm{C}$

and longitudinal sections (Fig. 9a, b), it reveals that a brittle intergranular fracture mode with an evidently straight crack initiated from specimen surface, as marked by the arrows in Fig. 9. This is identical to the quench crack under similar conditions [34, 35]. Kane et al. [34] regarded the fracture crack as a result of oxygen-induced dynamic embrittlement and deemed that the reason for this was probably oxygen which was readily available in water used for quenching, either from dissolved air or from a reduction reaction. When samples were cooled rapidly from high temperature, a sharp cooling rate generated the stress concentration to induce the penetration of oxygen into the core of a sharp crack and thus a high enough stress for decohesion to occur. The tiny quench cracks still existed during subsequent heat treatment and finally became a crucial factor of WC sample failure in tensile tests. Therefore, the WC method following solution treatment is not appropriate for Rene 80 alloy while the AC is an optimum option method.

\section{Conclusions}

1. The high cooling rate decreased the size of secondary $\gamma^{\prime}$ particles in the supersaturated matrix.
2. During aging at $1095{ }^{\circ} \mathrm{C} / 4 \mathrm{~h} / \mathrm{AC}$, the growth rates of $\gamma^{\prime}$ particles in $\mathrm{WC}$ and $\mathrm{AC}$ sample are higher. During aging at $1080{ }^{\circ} \mathrm{C} / 4 \mathrm{~h} / \mathrm{AC}$ and $870{ }^{\circ} \mathrm{C} / 12 \mathrm{~h} / \mathrm{AC}$, the $\gamma^{\prime}$ growth rates in three kinds of samples achieved to a close value.

3. The growth of fine $\gamma^{\prime}$ particles is more evident than that of coarse $\gamma^{\prime}$ particles during the low-temperature aging of $870{ }^{\circ} \mathrm{C} / 12 \mathrm{~h} / \mathrm{AC}$.

4. The aggregation of $\gamma^{\prime}$ particles of the grain boundaries contributed to the depletion of $\gamma^{\prime}$ particles on both sides.

5. The AC method following solution treatment was an optimal option for gaining relatively excellent elevated temperature mechanical properties.

Acknowledgment This work was supported by the National Natural Science Foundation of China (No. 51571191).

\section{References}

[1] A. Szczotok, Mater. Sci. Eng. 22, 012007 (2011)

[2] H. Yang, Z. Li, M. Huang, Modell. Simul. Mater. Sci. Eng. 22, 85009 (2014)

[3] Q. Feng, J.Y. Tong, Y.R. Zheng, M.L. Wang, W.J. Wei, H.L. Zhao, X.F. Yuan, X.F. Ding, Mater. China 31, 9 (2012)

[4] L. Xu, C. Cui, X. Sun, Mater. Sci. Eng. A 528, 7851 (2011) 
[5] J. Zhang, J. Li, T. Jin, X. Sun, Z. Hu, Mater. Sci. Eng. A 527, 3051 (2010)

[6] D.J. Kim, G.G. Lee, D.J. Kim, S.J. Jeong, J. Mater. Sci. Technol. 29, 1184 (2013)

[7] W.T. Loomis, J.W. Freeman, D.L. Sponseller, Metall. Trans. 3, 989 (1972)

[8] G. Lvov, V.I. Levit, M.J. Kaufman, Metall. Mater. Trans. A 35, 1669 (2004)

[9] J.P. Shingledecker, G.M. Pharr, Metall. Mater. Trans. A 43, 1902 (2012)

[10] X. Yang, S. Li, H. Qi, Int. J. Fatigue 75, 126 (2015)

[11] H.Y. Li, J.F. Sun, M.C. Hardy, H.E. Evans, S.J. Williams, T.J.A. Doel, P. Bowen, Acta Mater. 90, 355 (2015)

[12] J. Safari, S. Nategh, J. Mater. Process. Technol. 176, 240 (2006)

[13] G.A. Rao, M. Kumar, M. Srinivas, D.S. Sarma, Mater. Sci. Eng. A 355, 114 (2003)

[14] J. Li, R.P. Wahi, Acta Metall. 43, 507 (1995)

[15] T.J. Garosshen, G.P. McCarthy, Metall. Trans. A 16, 1213 (1985)

[16] J.S. Hou, J.T. Guo, L.Z. Zhou, Z.J. Li, Materials for Advanced Power Engineering 2006: Proceedings of the 8th Liège Conference, Germany, 2006, p. 435

[17] S.A. Sajjadi, H.R. Elahifar, H. Farhangi, J. Alloys Compd. 455, 215 (2008)

[18] J.L. Liu, T. Jin, J.J. Yu, X.F. Sun, H.R. Guan, Z.Q. Hu, Mater. Sci. Eng. A 527, 890 (2010)

[19] K.A. Unocic, J.P. Shingledecker, P.F. Tortorelli, JOM 66, 2535 (2014)

[20] J.S. Hou, L.Z. Zhou, C. Yuan, Z. Tang, J.T. Guo, X.Z. Qin, P.K. Liaw, Mater. Sci. Eng. A 560, 25 (2013)
[21] C. Yang, Y. Xu, H. Nie, X. Xiao, G. Jia, Z. Shen, Mater. Des. 43, 66 (2013)

[22] C. Wang, Y. Guo, J. Guo, L. Zhou, Mater. Sci. Eng. A 670, 178 (2016)

[23] P. Mao, Y. Xin, K. Han, W. Jiang, Acta Metall. Sin. (Engl. Lett.) 22, 365 (2009)

[24] Z.X. Shi, S.Z. Liu, J.R. Li, Acta Metall. Sin. (Engl. Lett.) 28, 1278 (2015)

[25] P.R. Bhowal, E.F. Wright, E.L. Raymond, Metall. Trans. A 21, 1709 (1990)

[26] Q. Wu, H. Song, R.W. Swindeman, J.P. Shingledecker, V.K. Vasudevan, Metall. Mater. Trans. A 39, 2569 (2008)

[27] M. Cabibbo, E. Gariboldi, S. Spigarelli, D. Ripamonti, J. Mater. Sci. 43, 2912 (2008)

[28] M. Huang, L. Zhuo, Z. Liu, X. Lu, Z. Shi, J. Li, J. Zhu, Mater. Sci. Eng. A 640, 394 (2015)

[29] H.U. Hong, I.S. Kim, B.G. Choi, M.Y. Kim, C.Y. Jo, Mater. Sci. Eng. A 517, 125 (2009)

[30] F. Wang, D. Ma, A. Bührig-Polaczek, Sci. Technol. Adv. Mater. 16, 025004 (2015)

[31] M. Shamsuddin, Physical Chemistry of Metallurgical Processes (Wiley, New York, 2016), p. 624

[32] L. Tan, Y. Yang, R.K. Nanstad, J.T. Busby, J. Phase Equilibria Diffus. 35, 524 (2014)

[33] D. Hadjiapostolidou, B.A. Shollock, 11th International Symposium on Superalloys, Warrendale, USA, 2008, p. 733

[34] W.M. Kane, U. Krupp, T. Jacobs, C.J. McMahon, Mater. Sci. Eng. A 402, 42 (2005)

[35] J. Gayda, P. Kantzos, J. Miller, Pract. Fail. Anal. 3, 55 (2003) 